\title{
ASSESSMENT OF HERBAL OIL EFFICIENCY AND KNOWLEDGE, ATTITUDE, AND PRACTICE STUDY REGARDING DIABETIC NEUROPATHY: A PILOT STUDY
}

\author{
PRANAY WAL*, RUCHI TIWARI \\ Department of Pharmacy, Pranveer Singh Institute of Technology, Kanpur, Uttar Pradesh, India. Email:pranaywal@gmail.com
}

Received: 22 December 2017, Revised and Accepted: 27 January 2018

\begin{abstract}
Objective: The objective of the current study was to assess the knowledge, attitude, and practices (KAPs) regarding diabetes and foot care in diabetic and non-diabetic participants as well as to detect the efficiency of nerve heed herbal oil (NHHO) prepared by Diabport Pvt. Ltd. on pain associated with nerves.
\end{abstract}

Methods: A statistical analysis of sociodemographic profile and KAP of 180 diabetic and non-diabetic participants (located in an old-age home, Kalyanpur, Kanpur, Uttar Pradesh, India) toward diabetes and foot care was performed. Samples of NHHO were suggested to apply for nerve pain.

Results: Statistical analysis of sociodemographic profile revealed that diabetes was independent of age, gender, and education level (p>0.5) while directly correlated to smoking $(\mathrm{p}<0.5)$. Dependent t-test explained the indirect correlation between knowledge and attitude $(\mathrm{p}<0.001)$ and knowledge and practice $(\mathrm{p}<0.05)$, which means that poor knowledge associated with poor practice. Chi-square test revealed that diabetic participants were having more knowledge $\left(\chi^{2}(1)=25.14, \mathrm{p}<0.001\right)$ and attitude $\left(\chi^{2}(1)=107.45, \mathrm{p}<0.001\right)$ toward diabetes and foot care, while there was no difference in terms of practice $\left(\chi^{2}(1)=3.10, p>0.05\right)$ in both the groups of participants. NHHO was found to be effective (84.21\%) in reducing initial symptoms of diabetic neuropathy.

Conclusion: It can be concluded that there is an urgent need to aware people regarding diabetes and its complications and provide continuous foot care education to patients. In this pilot study, NHHO was found to be effective as well as safe to treat nerve and joint pain.

Keywords: Sociodemographic profile, Knowledge; attitude; practices, Nerve heed herbal oil.

(C) 2018 The Authors. Published by Innovare Academic Sciences Pvt Ltd. This is an open access article under the CC BY license (http://creativecommons. org/licenses/by/4. 0/) DOI: http://dx.doi.org/10.22159/ajpcr.2018.v11i5.24381

\section{INTRODUCTION}

The WHO estimated that $80 \%$ of diabetes deaths occur in low- and middle-income countries and project that such deaths will double between 2016 and 2030. It has been further estimated that the global burden of type- 2 diabetes is expected to increase to 438 million by 2030 from 285 million people (recorded in 2010). Similarly, for India, this increase is estimated to be $58 \%$, from 51 million people in 2010 to 87 million in 2030. However, debates, discussions, and deliberations aside, the fundamental thing is to know what exactly diabetes is [1].

Diabetic peripheral neuropathy is a heterogeneous which frequently leads to foot ulcer. It is recommended to screen all individuals with diabetes at least annually [2]. Of all the complications of diabetes, those that occur in the foot are considered the most preventable. Poor knowledge and attitude toward diabetes and its complications, i.e. foot care and poor foot care practices were identified as important risk factors for foot problems in diabetes [3]. Evidence suggested that consistent patient education with prophylactic foot care for those judged to be at highest risk may reduce foot ulceration and amputations [4]. Changes in blood vessels and nerve often leads to ulceration and subsequent limb amputation. It is one of the most costly complications of diabetes, especially in communities with inadequate footwear. It results from both vascular and neurological disease processes. Regular inspection and good care of the foot can prevent amputations. Comprehensive foot programs can reduce amputation rates by $45-85 \%$ [5].

Although there is a large amount of literature on diabetic foot and the importance of foot care, there are limited published data on knowledge, attitude, and practices (KAPs) of foot care among diabetic patients in Uttar Pradesh, India. Thus, this study was conducted to assess the KAPs regarding diabetes and foot care in diabetic and non-diabetic participants as well as to detect the efficiency of nerve heed herbal oil (NHHO) prepared by Diabport Healthcare Pvt. Ltd. on pain associated with nerve. The information obtained will inform the current situation in relation to diabetic foot prevention strategies and will help to improve quality of care for diabetic patients to reduce the burden associated with diabetes foot complications as well as it can aid healthcare providers and policymakers to develop targeted self-management education programs for people with diabetes. Educating patients is likely to be effective if we are aware of their current knowledge and practices on foot care.

\section{METHODS}

Diabport Healthcare Pvt. Ltd. (Developed under Kalam Center for Innovation and Incubation of Startups) assessed general awareness about foot care with respect to KAPs in participants. The study was conducted in an old-age home located in Kalyanpur, Kanpur, Uttar Pradesh, on 180 old-age participants in July 2017. The aim of the study is to spread awareness about complications of diabetes as well as to assess the effectiveness of NHHO in terms of providing symptomatic relief in diabetic neuropathy (DN) patients.

The study population was subjected to self-administrative structured questionnaire which was developed by Diabport Healthcare Pvt. Ltd. and revised by two expert doctors in the field of diabetes and community medicine to enquire about KAP of foot care as well as NHHO was suggested to apply on foot. The questionnaire was composed of three parts:

A. Part I: Sociodemographic profile of participants including gender, age, qualification, their opinions regarding sources of their knowledge about diabetes, and their perception regarding their knowledge and training in diabetes as well as DN.

B. Part II: Multiple choice questions for the assessment of KAP of 
DN [6,7]. The scoring system was as follows:

- Knowledge score: One point for each correct answer of total 10 points. The cutoff point to pass the evaluation for knowledge considered $50 \%$ for correct answers of the total score. Not passed knowledge, if $<50 \%$, and passed, if $\geq 50 \%$.

- Attitude score: A total of 15 questions have been given to old-age people, and results were observed in terms of percentage agree or disagree. The cutoff point to pass the evaluation for attitude considered $50 \%$ for correct answers of the total score. Favorable attitude, if $\geq 50 \%$, and unfavorable attitude, if $<50 \%$.

- Practice score: Practice score was calculated in percentage; one point for each positive answer out of 12 questions. The cutoff point to pass the evaluation for practice considered $75 \%$ for correct answers of the total score. Appropriate, if $\geq 75 \%$, and inappropriate, if $<75 \%$.

C. Part III: Effectiveness of herbal oil was screened by entering each symptom of DN in a binary score indicating the presence or absence of symptom ( 0 = absent, 1 = slight, and 2 = present $)$, and then, a total score was calculated by adding these symptom scores. The cutoff point to pass the evaluation for practice considered $70 \%$ for the effectiveness of herbal oil to the total score. Effective if $\geq 70 \%$ and ineffective if $<70 \%$.

\section{Ethical considerations}

Ethical approval was granted by the Ethics Committee, GSVM Medical College, Kanpur, India. Permission to collect data was granted from the hospital's authorities. Consent forms were given to patients read and sign, and those who could not read it were explained to them and made a thumbprint. To maintain confidentiality, all questionnaires were coded and did not bear patients names.

\section{Statistical design}

Statistical analysis data were analyzed using the Statistics Package for Social Science (SPSS) version 21 for Windows. All continuous data were expressed in terms of mean (SD), and categorical variables were expressed inform of number and percent. Differences in continuous variables between groups were analyzed using independent t-test. In addition, the comparison between two groups was done by Pearson correlation (Chi-square test) for categorical variables [7]. The effect of questionnaire on KAP was measured by one-way ANOVA and Turkey's post hoc tests. Statistical significance was considered at $\mathrm{p}<0.05$ and a higher significance at $\mathrm{p}<0.001$. A Chi-square test was applied to compare the KAP score as well as risk factors for foot ulcer development between patients with and without diabetes using SPSS software.

\section{RESULTS}

A paired samples t-test was conducted to compare demographic and socioeconomic characteristics of diabetic and non-diabetic participants. The calculated $t$-value was greater than the table value at an alpha level of 0.05 . The p-value was less than the alpha level: $p<0.05$. A Chi-square test for independence was calculated comparing the frequency of diabetic and non-diabetic individuals in two different age groups $(<60$ and $>60)$. No significant interaction was found $\left(\chi^{2}(1)=0.16, p>0.05\right)$. In the same way, Chi-square test was applied to other demographic and socioeconomic characteristics for gender $\left(\chi^{2}(1)=0.27, \mathrm{p}>0.05\right)$ and education level $\left(\chi^{2}(3)=4.42, \mathrm{p}>0.05\right)$ of participants. When the same test was applied for the inference of smoking on diabetes, results revealed that there is a significant difference $\left(\chi^{2}(2)=13.18, p<0.05\right)$ between the groups of participants (Table 1). Prepared questionnaire on knowledge of DN was studied among the study population (Table 2).

The total positive score for all knowledge questions was $18 \%$. To test the hypothesis that the knowledge and attitude means were equal, dependent samples t-test was performed. The null hypothesis of an equal correlation between knowledge and attitude was rejected t $(14)=-7.4, p<0.001$. Sisnce our paired samples, result revealed that the mean number of attitude $(M=62)$ was greater than the mean number of knowledge $(M=12)$. In the same way, dependent samples t-test was conducted to compare knowledge and practice of participants (t $(14)=-2.62, p<0.05)$ towards DN. Mean number of practice $(M=26)$ was greater than the mean number of knowledge $(M=12) .62 .27 \%$ of participants showed favorable attitude (passed the study), while $37.73 \%$ of participants showed unfavorable attitude toward DN (Table 3). Paired samples t-test was conducted to identify the significant difference between attitude and practice of participants $(t)=3.97, p \leq 0.001)$ on DN. Mean number of attitude $(M=62.26)$ was greater than practice $(M=26)$. Table 4 summarizes foot care practices for the study population. A one-way ANOVA was conducted to evaluate the null hypothesis that there is no difference in KAP toward DN in the study population $(\mathrm{N}=180)$. The $\mathrm{F}$ test for $\operatorname{KAP}(2,34)$ was 17.80 , which was statistically significant at $5 \%$ level $(p<0.001)$. Table 5 summarizes the significant difference between diabetic and non-diabetic participants with respect to KAP toward DN, and it was found $\left(\chi^{2}(1)=25.14, p<0.001\right),\left(\chi^{2}(1)=107.45, p<0.001\right)$, and $\left(\chi^{2}(1)=3.10, p>0.05\right)$ for KAP, respectively. Painful DN has debilitating consequences with a significant impact on quality of life and cost of management [8]. The results of the present study showed that NHHO was effective $(84.21 \%)$ as well as safe in reducing symptoms of neuropathic pain (Table 6).

\section{DISCUSSION}

Statistical results revealed that significant difference was found between diabetic and non-diabetic participants with respect to sociodemographic profiles. Null hypothesis rejected and concluded that there is a difference between means. We analyzed inference of age of diabetic and non-diabetic individuals to examine whether diabetes is independent to age or not. Chi-square test suggested that diabetes is independent of age [9]. It was also found that diabetes was independent of gender and education level. When the same test was applied for the inference of smoking on diabetes, results showed a

Table 1: Demographic and socioeconomic characteristics of diabetic patients

\begin{tabular}{|c|c|c|c|c|}
\hline Characteristics & Total population (total=180) & Diabetes present & Diabetes absent & p value \\
\hline \multicolumn{5}{|l|}{ Age } \\
\hline$<60$ & 10 & 05 & 05 & \multirow[t]{2}{*}{0.68} \\
\hline$>60$ & 170 & 96 & 74 & \\
\hline \multicolumn{5}{|l|}{ Gender } \\
\hline Male & 164 & 93 & 71 & \multirow[t]{2}{*}{0.60} \\
\hline Female & 16 & 08 & 08 & \\
\hline \multicolumn{5}{|l|}{ Educational level } \\
\hline No formal education & 27 & 16 & 11 & \multirow{4}{*}{0.22} \\
\hline Primary education & 49 & 29 & 20 & \\
\hline Secondary and vocational & 52 & 23 & 29 & \\
\hline Post-secondary education & 52 & 33 & 19 & \\
\hline \multicolumn{5}{|l|}{ Smoking } \\
\hline Currently smoking & 30 & 24 & 06 & \multirow[t]{3}{*}{0.001} \\
\hline Past smoker & 27 & 19 & 08 & \\
\hline Never smoked & 123 & 58 & 65 & \\
\hline
\end{tabular}


Table 2: Questionnaire for patient's knowledge score in percentage

\begin{tabular}{|c|c|c|}
\hline \multirow[t]{2}{*}{ Knowledge } & \multicolumn{2}{|c|}{ Response (\%) } \\
\hline & Positive & Negative \\
\hline What is diabetes? & 54 & 46 \\
\hline Do you know what DN is? & 15 & 85 \\
\hline $\begin{array}{l}\text { Do you know constantly elevated glucose } \\
\text { level can lead to DN? }\end{array}$ & 14 & 86 \\
\hline $\begin{array}{l}\text { Do you know numbness in legs and/or feet } \\
\text { may lead to DN? }\end{array}$ & 13 & 87 \\
\hline How DN can be prevented? & 14 & 86 \\
\hline $\begin{array}{l}\text { Do you know DN is related to nerve } \\
\text { damage? }\end{array}$ & 15 & 85 \\
\hline $\begin{array}{l}\text { Which one is the correct foot cares in a } \\
\text { diabetic person? }\end{array}$ & 18 & 82 \\
\hline $\begin{array}{l}\text { Do you know the relation between diabetes } \\
\text { and nerve? }\end{array}$ & 09 & 91 \\
\hline What treatments are available for DN? & 08 & 92 \\
\hline $\begin{array}{l}\text { Do you know other complications of } \\
\text { diabetes? }\end{array}$ & 20 & 80 \\
\hline Total percentage & $\begin{array}{l}18.0 \text { (not } \\
\text { passed) }\end{array}$ & 82.0 \\
\hline
\end{tabular}

DN: Diabetic neuropathy

Table 3: Questionnaire for patient's attitude toward DN in percentage

\begin{tabular}{|c|c|c|}
\hline \multirow[t]{2}{*}{ Attitude } & \multicolumn{2}{|c|}{ Response (\%) } \\
\hline & Agree & Not agree \\
\hline $\begin{array}{l}\text { Do you ever have any burning pain in } \\
\text { your legs and/or feet? }\end{array}$ & 57 & 43 \\
\hline $\begin{array}{l}\text { Do you get muscle cramps in your legs } \\
\text { and/or feet? }\end{array}$ & 42 & 58 \\
\hline $\begin{array}{l}\text { Have you ever had an open sore on your } \\
\text { foot? }\end{array}$ & 71 & 29 \\
\hline $\begin{array}{l}\text { Has your doctor ever told you that you } \\
\text { have DN? }\end{array}$ & 91 & 09 \\
\hline $\begin{array}{l}\text { Do you feel weak all over most of the } \\
\text { time? }\end{array}$ & 40 & 60 \\
\hline Are your symptoms worse at night? & 37 & 63 \\
\hline Do your legs hurt when you walk? & 46 & 54 \\
\hline $\begin{array}{l}\text { Are you able to sense your feet when you } \\
\text { walk? }\end{array}$ & 41 & 59 \\
\hline $\begin{array}{l}\text { Is the skin on your feet so dry that it } \\
\text { cracks open? }\end{array}$ & 56 & 44 \\
\hline $\begin{array}{l}\text { Do you know foot ulcers (open sores) are } \\
\text { caused by poor medical care? }\end{array}$ & 71 & 29 \\
\hline $\begin{array}{l}\text { Do you know dry skin on the feet can } \\
\text { cause foot ulcers? }\end{array}$ & 77 & 23 \\
\hline $\begin{array}{l}\text { Do you know lost or reduced feeling } \\
\text { means poor circulation in my feet? }\end{array}$ & 75 & 25 \\
\hline $\begin{array}{l}\text { Do you know wearing shoes that fit } \\
\text { properly can prevent foot ulcers from } \\
\text { occurring? }\end{array}$ & 87 & 13 \\
\hline $\begin{array}{l}\text { Do you know lost or reduced feeling in } \\
\text { feet could lead to injuries? }\end{array}$ & 830 & 17 \\
\hline $\begin{array}{l}\text { Diabetes doctors can prevent foot } \\
\text { ulcers (open sores) from occurring }\end{array}$ & 60 & 40 \\
\hline Total percentage & $\begin{array}{l}62.27 \\
\text { (passed) }\end{array}$ & $\begin{array}{l}37.73 \\
\text { (not passed) }\end{array}$ \\
\hline
\end{tabular}

DN: Diabetic neuropathy

direct inference of smoking on the occurrence of diabetes. Participants were found to be failed with respect to knowledge [10]. When t-test was applied to knowledge and attitude, it was concluded that there was a statistically significant difference between the knowledge and attitude of individuals toward DN conditions. The study suggested that
Table 4: Questionnaire for patient's foot care practice in percentage

\begin{tabular}{lll}
\hline Practice & Response (\%) & \\
\cline { 2 - 3 } & Appropriate & Inappropriate \\
\hline $\begin{array}{l}\text { Are you performing proper } \\
\text { foot care? }\end{array}$ & 60 & 40 \\
$\begin{array}{l}\text { Inspect footwear before } \\
\text { wearing? }\end{array}$ & 58 & 42 \\
$\begin{array}{l}\text { Walk bare feet in the house } \\
\text { often? }\end{array}$ & 77 & 23 \\
$\begin{array}{l}\text { Walk bare feet outside the } \\
\text { house often? }\end{array}$ & 09 & 91 \\
$\begin{array}{l}\text { Daily washing the feet? } \\
\text { Talcum powder use for }\end{array}$ & 38 & 62 \\
$\begin{array}{l}\text { keeping the interdigital space } \\
\text { dry? }\end{array}$ & 26 & 74 \\
$\begin{array}{l}\text { Keep the skin of feet soft to } \\
\text { prevent dryness? }\end{array}$ & 06 & \\
$\begin{array}{l}\text { Daily change of socks? } \\
\text { Trim toenails straight with } \\
\text { care? }\end{array}$ & 11 & 94 \\
$\begin{array}{l}\text { Warning signs for which } \\
\text { consultation is required? }\end{array}$ & 49 & 89 \\
$\begin{array}{l}\text { Using warm water for washing } \\
\text { feet? }\end{array}$ & 14 & 51 \\
$\begin{array}{l}\text { Drying the feet after washing? } \\
\text { Total percentage }\end{array}$ & 19 & 77 \\
\hline
\end{tabular}

Table 5: Comparing KAP scores on DN between patients with and without diabetes

\begin{tabular}{llll}
\hline Response (\%) & $\begin{array}{l}\text { \% Individuals } \\
\text { with diabetes } \\
\text { (n=101) }\end{array}$ & $\begin{array}{l}\text { \% Individuals } \\
\text { without diabetes } \\
\text { (n=79) }\end{array}$ & p value \\
\hline Knowledge & & 3 & $<0.001$ \\
$\quad$ Yes & 29 & 97 & \\
$\quad$ No & 71 & 18 & $<0.001$ \\
Attitude & 91 & 82 & \\
$\quad$ Agree & 09 & 21 & $>0.05$ \\
$\quad$ Not agree & 32 & 79 & \\
$\begin{array}{l}\text { Practice } \\
\text { Appropriate }\end{array}$ & & & \\
Inappropriate & 68 & &
\end{tabular}

Table 6: Effect of NHHO on DN symptoms

\begin{tabular}{lll}
\hline Symptoms of DN & Score* $^{*}$ & Side effects \\
\hline Joint pain & 1 & \\
Weakness & 0 & No reaction \\
Numbness of extremities & 0 & \\
Loss of sensation in nerves & 0 & \\
Burning sensation in nerves & 0 & \\
\hline${ }^{*} 0=$ absent, $1=$ slight, $2=$ present & &
\end{tabular}

participants with attitude toward DN can help prevent neuropathy in individuals significantly more than having knowledge of DN [11]. Statistical results also suggested narrow significant difference between knowledge and practice of participants involved in the study, which proved that knowledge had a direct impact on practice but to a small extent [12]. Thus, it can be concluded that participants with good foot care practice can help to eradicate neuropathy in individuals significantly more than knowledge of DN in individuals. Paired samples t-test between attitude and practice rejected the null hypothesis. Thus, it can be concluded that attitude of participants had a direct impact on practice of DN. Foot self-inspection was done regularly (6-7 days 
a week) by 180 participants, and it was found that majority of the population had inappropriate foot care practices even they had good knowledge and attitude. Null hypothesis was rejected and results revealed that people having good attitude while poor knowledge and practice towards foot care. When $29 \%$ of diabetic participants had good knowledge about DN, it was only $3 \%$ among participants without diabetes with good knowledge. Similarly, the attitude of participants toward DN was found to be significantly different in diabetic and nondiabetic participants [13]. No significant difference in practice toward adopting proper foot care was observed between the participants with and without diabetes. It has been concluded that there is a difference in knowledge and attitude toward DN in diabetic and non-diabetic participants in the study population, while practice toward foot care was found to be similar in diabetic and non-diabetic participants [14]. Foot ulcer is a disabling complication and common among people with diabetes mellitus $[15,16]$. The disability and possible progression to the amputation of digits and limbs make it a serious issue [17]. Application of herbal oil showed no adverse effects in the present study, which indicated the safety of this formulation. Active ingredients present in this herbal formulation are known to possess anti-inflammatory and analgesic actions, which aid in alleviating the increased inflammation associated with painful DN.

\section{CONCLUSION}

Knowledge of foot care is low among patients with diabetes. Their knowledge can be improved by education and proper foot care modeling by health-care providers. It is essential to assess patients' beliefs and behavior so as to offer education and utilize educational methods that facilitate them to care for their feet efficiently. Knowledge alone, however, does not always lead to change in behavior and practice toward foot care. There is a need for continuous education on foot care to improve patients' knowledge of risks and foot self-care practices. Furthermore, our results showed that daily application of NHHO prepared by Diabport Healthcare Pvt. Ltd. significantly reduced the symptoms of painful DN without any adverse side effect. The herbal oil may be effective in treating painful DN along with routine standard care. It must, however, be emphasized that intensive hyperglycemic control also plays an important role in reducing neuropathic pain in patients with diabetes.

\section{CONFLICT OF INTEREST}

There is no conflict of interest.

\section{REFERENCES}

1. Maliki R, India is Diabetes Capital of India. The Times of India; 2017. Available from: http://www.timesofindia.indiatimes.com/life-style/ health-fitness/health-news/India-is-the-diabetes-capital-of-the-world/ articleshow/50753461.cms. [Last cited on 2017 Aug 08].

2. Wu J, Zhang X, Zhang B. Efficacy and safety of puerarin injection in treatment of diabetic peripheral neuropathy: A systematic review and meta-analysis of randomized controlled trials. J Tradit Chin Med 2014;34:401-10.

3. American Diabetes Association. Standards of medical care in diabetes. Diabetes Care 2006;29:S4-42.

4. Chandalia HB, Singh D, Kapoor V, Chandalia SH, Lamba PS. Footwear and foot care knowledge as risk factors for foot problems in Indian diabetics. Int J Diabetes Dev Ctries 2008;28:109-13.

5. Calle-Pascual AL, Durán A, Benedí A, Calvo MI, Charro A, Diaz JA, et al. A preventative foot care programme for people with diabetes with different stages of neuropathy. Diabetes Res Clin Pract 2002;57:111-7.

6. Saranya P, Swathi S, Kousalya K, Praveen D. A prospective interventional study of knowledge, attitude and practice (KAP) towards tuberculosis among patients with koch's disease. Int J Pharm Pharm Sci 2016;8:58-61

7. Gholap MC, Mohite VR. To assess the knowledge and practice regarding foot care among Diabetes patients at Krishna hospital, Karad. Indian J Sci Res 2013;4:69-75.

8. Niroomand M, Ghasemi SN, Karimi-Sari H, Kazempour-Ardebili S, Amiri P, Khosravi MH, et al. Diabetes knowledge, attitude and practice (KAP) study among Iranian in-patients with Type-2 diabetes: A crosssectional study. Diabetes Metab Syndr 2016;10:S114-9.

9. About Diabetes. World Health Organizations. Available from: http:// www.who.int/diabetes/action_online/basics/en/index3.html. [Last cited on 2017 Aug 05].

10. Mabrouk N, Abdou M, Nour-Eldin H, Solyman El-Foly AA, Omar SA, Sliem HA. Knowledge, attitude, and practice of family physicians regarding diabetic neuropathy in family practice centers: Suez Canal University. Int J Med Pub Health 2013;3:230-4.

11. Chiwanga FS, Njelekela MA. Diabetic foot: Prevalence, knowledge, and foot self-care practices among diabetic patients in Dar es Salaam, Tanzania-a cross-sectional study. J Foot Ankle Res 2015;8:20-7.

12. Blessy A, Jobin T, Alexander R, Sheen AV, Gloria KS. Assessment and evaluation on knowledge, attitude, and practice towards medication therapy management among community of davangere city. Asian J Pharm Clin Res 2017;10:380-3.

13. George H, Rakesh PS, Krishna M, Alex R, Abraham VJ, Kuryan G, et al. Foot care knowledge and practices and the prevalence of peripheral neuropathy among people with diabetes attending a secondary care rural hospital in Southern India. J Family Med Prime Care 2013;2:27-32.

14. Bohorquez Robles R, Compeán Ortiz LG, González Quirarte NH, Berry DC, Aguilera Pérez P, Piñones Martínez S, et al. Knowledge and practices of diabetes foot care and risk of developing foot ulcers in México may have implications for patients of Méxican heritage living in the US. Diabetes Educ 2017;43:297-303.

15. Vijayakumar PR, Kalshetti SM, Bhatt JK. Supplementation of $\alpha$-lipoic acid in diabetic peripheral neuropathy: A prospective open label randomized controlled trial. Int J Pharm Pharm Sci 2014;6:90-3.

16. Al-mahmood SM, Razak TA, Ahmad NN, Mohamed AH, Abdullah ST Factors influencing the severity of pain in patients with peripheral diabetic neuropathy. Asian J Pharm Clin Res 2017;10:306-9.

17. Prasad SN, Muralidhara M. Analysis of the antioxidant activity of geraniol employing various in-vitro models: Relevance to neurodegeneration in diabetic neuropathy. Asian J Pharm Clin Res 2017;10:101-5. 